\title{
PERFIL BIOQUÍMICO E HEMATOLÓGICO ASSOCIADOS À OCORRÊNCIA DA GESTAÇÃO EM NOVILHAS NELORE
}

\author{
[Biochemical and hematological profile associated with pregnancy in Nellore heifers]
}

\author{
Lucas Jacomini Abud ${ }^{1 *}$, Cátia Oliveira Guimarães Abud ${ }^{2}$, Gustavo Lage Costa ${ }^{3}$, Maria Clorinda Soares \\ Fioravanti $^{4}$, Carlos Frederico Martins ${ }^{5}$, Concepta Margaret McManus Pimentel ${ }^{6}$, José Robson Bezerra \\ Sereno ${ }^{7}$ \\ ${ }^{1}$ Docente da Universidade Federal do Sul e Sudeste do Pará, Campus de Xinguara. \\ ${ }^{2}$ Médica Veterinária da Universidade Federal do Sul e Sudeste do Pará, Campus de Xinguara. \\ ${ }^{3}$ Pós-Doutorando do Programa de Pós-Graduação em Ciência Animal da Escola de Veterinária e Zootecnia da Universidade \\ Federal de Goiás, Campus Samambaia. \\ ${ }^{4}$ Docente da Escola de Veterinária e Zootecnia da Universidade Federal de Goiás, Campus Samambaia. \\ ${ }^{5,7}$ Pesquisadores da Embrapa Cerrados. \\ ${ }^{6}$ Docente do Instituto de Ciências Biológicas da Universidade de Brasília, Campus Darcy Ribeiro.
}

\begin{abstract}
RESUMO - O objetivo desse estudo foi verificar a relação do perfil bioquímico e hematológico com a ocorrência de gestação em novilhas Nelore criadas a pasto. Foram acompanhadas 56 novilhas no período de 17 meses, realizou-se nove colheitas com intervalos de dois meses no qual foram avaliados idade e peso; e quantificado as concentrações séricas de proteína total, magnésio, fósforo, cálcio, albumina, glicose, colesterol, ureia, atividade sérica da gama glutamiltransferase, aspartato aminotransferase e fosfatase alcalina, contagem de hemácias, de leucócitos, de plaquetas, valor de hematócrito, teor de hemoglobina e fibrinogênio para relacionar possíveis alterações no perfil bioquímico e hematológico com a ocorrência da gestação em novilhas. Das 56 novilhas avaliadas, $66,07 \%$ ficaram gestantes com intervalo de idade de 28,70 $\pm 2,73$ a 30,55 $\pm 2,80$ meses e peso entre $328,92 \pm 32,47$ a $386,81 \pm 46,56 \mathrm{~kg}$. Os animais que gestaram obtiveram maiores valores para as variáveis albumina, ureia, hemácias, hemoglobina e hematócrito e menores valores para AST, ALP e GGT. Dentre as probabilidades associadas a ocorrência de gestação, pode-se destacar as variáveis idade, peso e proteína total. Conclui-se neste estudo que a ocorrência de gestação em novilhas Nelore criadas a pasto apresentou relação com as variáveis proteína total, alumina, ureia, AST, ALP, GGT do perfil bioquímico e com as variáveis hemácias, hematócrito, hemoglobina e leucócitos do perfil hematológico.
\end{abstract}

Palavras-Chave: Bos taurus indicus; idade; peso; precocidade sexual.

\begin{abstract}
The objective of this study was to determine the relationship between biochemical and hematological profile and the occurrence of pregnancy in Nellore heifers raised on pasture. We evaluated the heifers (56) during 17-month, and carried out nine collections every two months to evaluate age and weight, and determine serum concentrations of total protein, magnesium, phosphorus, calcium, albumin, glucose, cholesterol, urea, serum activity of gamma glutamyl transferase, aspartate aminotransferase, alkaline phosphatase, erythrocyte, leukocyte, platelet counts, hematocrit value, hemoglobin and fibrinogen to relate possible changes in hematological and biochemical profile with the occurrence of pregnancy in heifers. Of the 56 heifers evaluated, $66.07 \%$ were pregnant with age range from $28.70 \pm 2.73$ to $30.55 \pm 2.80$ months and weighing $328.92 \pm 32.47$ to $386.81 \pm 46.56 \mathrm{~kg}$. The animals that gave birth presented higher values of the variables albumin, urea, erythrocytes, hemoglobin and hematocrit, and lower values for AST, ALP and GGT. Among the probabilities associated to pregnancy, age, weight and total protein can be highlighted. We concluded that the occurrence of pregnancy in heifers raised on pasture was related to variables total protein, albumina, urea, AST, ALP, and GGT of the biochemical profile, and the variables hematocrit, hemoglobin and leukocyte of the blood profile.
\end{abstract}

Keywords: Bos taurus indicus; age; weight; sexual precocity.

\footnotetext{
* Autor para correspondência. E-mail: lucas.abud@unifesspa.edu.br Recebido: 10 de dezembro de 2015.

Aceito para publicação: 15 de fevereiro de 2016.
} 


\section{INTRODUÇÃO}

A puberdade é um evento fisiológico importante para a vida produtiva de novilhas, por estar associada ao início da atividade reprodutiva. Estas modificações estão relacionadas com a diminuição da sensibilidade do eixo hipotalâmico-hipofisário a ação do estrógeno, que resulta no aumento na pulsatilidade de LH consequentemente ovulação do folículo dominante, sendo esta seguida da formação de um corpo lúteo funcional (Cardoso \& Nogueira 2007). A ocorrência da puberdade é influenciada por diversos fatores como nutrição, idade, genótipo, estação do ano, peso corporal e ambiente social (Rorie et al., 2002).

Diversos estudos foram realizados na tentativa de antecipar a ocorrência da puberdade e consequentemente a idade a primeira gestação, dentre estes a utilização de terapias hormonais (Claro Júnior et al., 2010), uso da bioestimulação (Oliveira et al., 2009; Fiol et al., 2010), a seleção de animais sexualmente precoce (Boligon \& Albuquerque 2011) e o manejo nutricional que é amplamente estudado por ser de fácil aplicação e ter alta influencia na ocorrência desses eventos (Pilau \& Lobato, 2009).

Manejos nutricionais que proporcionem alto ganho de peso, rápido desenvolvimento corporal e alto escore de condição corporal, estão associados à redução da idade a primeira gestação e aumento nas taxas de novilhas gestantes (Vaz \& Lobato, 2010a). Para avaliar o balanço nutricional utiliza-se a avaliação do escore de condição corporal, como método auxiliar a esta avaliação pode-se utilizar o perfil bioquímico, esta metodologia analisa os componentes sanguíneos e reflete de maneira confiável o equilíbrio homeostático do animal (González et al., 2000).

O perfil bioquímico não é um exame nutricional, mas um método que permite observar a capacidade de homeostase do animal sendo indicador do balanço metabólico, portanto, pode ser usado para orientar as indicações dos nutricionistas (Wittwer, 2000).

O objetivo desse estudo foi verificar a relação do perfil bioquímico e hematológico com a ocorrência de gestação em novilhas Nelore criadas a pasto.

\section{MATERIAL E MÉTODOS}

O trabalho foi realizado na área experimental da Embrapa Cerrados localizado em Planaltina, Distrito Federal. O clima na região é caracterizado como tropical-quente-subúmido com duas estações definidas: uma seca (maio a setembro) e outra chuvosa (outubro a abril) (Embrapa Cerrados -
CPAC: www.agritempo.gov.br/agroclima/sumario). Foram acompanhadas 56 novilhas da raça Nelore com idade média de $16,57 \pm 2,52$ meses e peso médio de $227,11 \pm 34,32$, oriundas do plantel de seleção da empresa. O período experimental teve duração de 17 meses, tendo início em fevereiro de 2008 e término em junho de 2009, neste período as médias de temperatura estiveram entre 16,1 a $27,9^{\circ} \mathrm{C}$, com precipitação pluviométrica de 1414,80 $\mathrm{mm}$.

Os animais foram mantidos sob as mesmas condições, em pastagens cultivadas de Brachiaria decumbens, com taxa de lotação de 1UA/ha, sob pastejo contínuo, com sal mineralizado oferecido em cochos cobertos. O manejo sanitário, desverminação e vacinação, foram realizados de acordo com o calendário profilático-sanitário da região do Distrito Federal.

Dois touros com avaliação andrológica positiva foram introduzidos no primeiro mês de colheita no rebanho composto por 56 novilhas visando identificar as fêmeas que gestaram, condição determinante para finalização das colheitas. O diagnóstico de gestação foi realizado com auxílio de um aparelho de ultrassonografia por via transretal.

Durante o período experimental de 17 meses, a cada dois meses foram realizadas as amostragens, sendo obtido o peso, diagnóstico de gestação e a colheita de sangue para caracterização do perfil bioquímico e hematológico, totalizando nove colheitas de cada parâmetro.

O sangue foi colhido por venopunção da jugular em três tubos de ensaio a vácuo (Vacuntainer ${ }^{\circledR}$ ) contendo EDTA, fluoreto e sem anticoagulante. O sangue total obtido em tubos com EDTA foi utilizado para realização das análises hematológicas e as outras amostras sanguíneas foram centrifugadas em temperatura ambiente a $4695 \mathrm{~g}$ por 10 minutos para a obtenção de plasma e soro, sendo o último estocado a $-20^{\circ} \mathrm{C}$.

A determinação da glicose foi feita com as amostras de plasma dos tubos com fluoreto, sendo usado reagente comercial (Labtest Diagnóstica S. A.®, Lagoa Santa) com leitura em analisador bioquímico automático (espectrofotômetro Bioplus®, Bio-2000 IL-A). A separação do plasma ocorreu dentro de no máximo quatro horas após a colheita e as determinações ocorreram em um período máximo de 24 horas.

Nas amostras de soro foram quantificados proteína total, magnésio, fósforo, cálcio, albumina, colesterol, ureia, atividade sérica da gama glutamiltransferase (GGT), aspartato 
aminotransferase (AST) e fosfatase alcalina (ALP) utilizando reagentes comerciais (Labtest Diagnóstica S. A.®, Lagoa Santa) com leitura em analisador bioquímico automático (espectrofotômetro Bioplus®, Bio-2000 IL-A), sendo as reações processadas a temperatura de $37^{\circ} \mathrm{C}$. A globulina foi determinada por meio da subtração dos valores de albumina dos valores de proteína total.

As análises hematológicas foram realizadas dentro de 24 horas, em analisador hematológico veterinário automático $(\mathrm{ABX}$ Vet $\mathrm{ABC} \AA$, Horiba ABX Diagnostics). Foram determinados os valores de hematócrito, número total de hemácias, teor de hemoglobina, contagem total de leucócitos e plaquetas. Além do hemograma utilizou-se o sangue total para obtenção do plasma e determinação do fibrinogênio, baseando-se na sua precipitação em banho-maria a $56^{\circ} \mathrm{C}$ e posterior leitura em refratômetro manual, conforme Schalm et al. (1981).

As análises bioquímicas e hematológicas foram realizadas no Laboratório de Pós-Graduação em Ciência Animal da Escola de Veterinária e Zootecnia da Universidade Federal de Goiás, Campus Samambaia, Goiânia, Goiás.

Para avaliar a relação dos componentes bioquímicos e hematológicos com a ocorrência da gestação separaram-se as novilhas em dois grupos, gestantes e não gestantes. Após a separação realizou-se a comparação das médias de cada variável entre os grupos utilizando teste T. Para avaliar o efeito dos componentes do perfil bioquímico e hematológico sobre a ocorrência da gestação utilizou-se os testes de regressão logística. As associações entre as características foram investigadas usando análise de correlação e componentes principais. As análises foram realizadas com o auxílio do softwre Statistical Analysis System - SAS ${ }^{\circledR}$ (2004).

\section{RESULTADO E DISCUSSÃO}

Das 56 novilhas avaliadas, $66,07 \%$ ficaram gestantes no intervalo de idade de $28,70 \pm 2,73$ a $30,55 \pm 2,80$ meses e peso entre $328,92 \pm 32,47$ a $386,81 \pm 46,56 \mathrm{~kg}$, e as novilhas não gestantes finalizaram as avaliações com idade e peso de $31,04 \pm 1,40$ meses e $379,47 \pm 36,86 \mathrm{~kg}$. A idade observada neste experimento é elevada quando se trata de sistema de produção intensivo, para o qual se busca antecipar o início da atividade reprodutiva das fêmeas, segundo Beretta et al. (2001), a antecipação da idade ao primeiro parto associada a uma elevada taxa de natalidade resulta na melhor eficiência do sistema produtivo.

Neste estudo a idade média à primeira gestação das novilhas está dentro dos valores descritos para a raça. Segundo Nogueira (2004), a idade média brasileira para a primeira concepção em bovinos de corte é de 31 meses, podendo ter variações de 16 a 40 meses dependendo das condições ambientais. Estão descritos na literatura intervalos de idade no início da vida reprodutiva muitos amplos para a raça Nelore, estes variam de 16 a 19 meses (Oliveira et al., 2009; Shiotsuki et al., 2009), 24 a 28 meses (Silva et al., 2005; Vieira et al., 2006) e de 40.8 meses (Sereno et al., 2001).

A variação de resultados do presente estudo e os acima citados, para idade ao início da vida reprodutiva é justificada pelas diferenças genéticas dos animais de cada estudo e pelos manejos adotados em cada experimento. Segundo Boligon et al. (2008), o manejo adotado em cada propriedade influência na manifestação das características reprodutivas principalmente no início da atividade reprodutiva.

Os animais tiveram elevada idade à primeira gestação, isto pode ser justificada pela baixa taxa de crescimento ao longo do experimento (Figura 1) devido a baixa qualidade de forragem na época seca do ano, segundo Euclides et al. (2001) e Reis et al. (2012), a redução da qualidade da forragem nos períodos de seca resulta no baixo desenvolvimento dos animais ou a perda de peso dos mesmos. Euclides et al. (2001) relataram que a redução da qualidade da forragem é resultante do acúmulo de frações recusadas das plantas pelos animais durante o pastejo contínuo.

A elevada idade à primeira concepção e o baixo desenvolvimento observados neste experimento pode ser evitado buscando alternativas de manejo, como suplementação e melhoria das pastagens, para proporcionar maiores ganhos de peso e maiores pesos no período de acasalamento como descrito por Pilau \& Lobato (2009); Vaz \& Lobato (2010ab); Gojjam et al. (2011). 


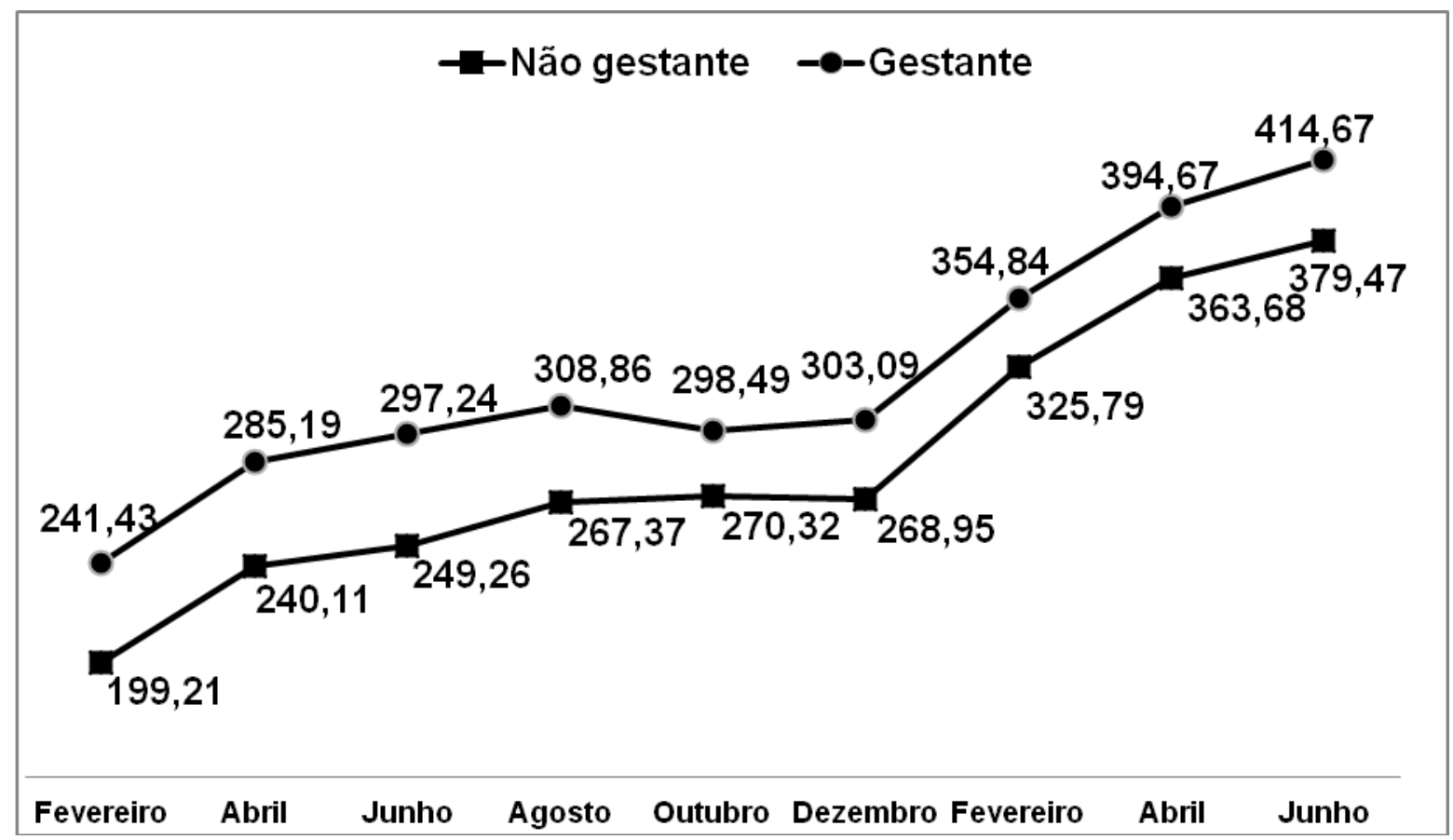

Figura 1. Peso médio das novilhas Nelore criadas a pasto durante o período experimental.

A taxa de gestação de $66 \%$ encontrada neste estudo está dentro dos intervalos descritos na literatura para novilhas da raça Nelore que varia de 18 a 83,7 $\%$ (Oliveira et al., 2009; Claro Júnior et al., 2010; Cordova \& Ciffini, 2010; Cabral et al., 2013). Para aumentar essa, pode-se utilizar alternativas que estimulem a atividade ovariana de novilhas (Cardoso \& Nogueira, 2007), tais como bioestimulação (Oliveira et al., 2009; Menezes et al., 2010), tratamentos hormonais (Claro Júnior et al., 2010; Cabral et al., 2013) e utilização de manejos nutricionais que proporcionem rápido desenvolvimento em idades jovens (Vaz \& Lobato, 2010a). Estas alternativas proporcionam o incremento de 15 a $160 \%$ na taxa de gestação.

Os resultados do perfil bioquímico e hematológico estão representados na tabela 1. Ao confrontar os valores do perfil bioquímico das novilhas que não gestaram e que gestaram com os valores referenciados por Fagliari et al., (1998), Vásquez \& Herrera (2003) e Lima \& Fioravanti (2010) para a raça Nelore, observou-se que os mesmos estão próximos aos normais descritos por estes autores. Os valores dos componentes do perfil hematológico das novilhas também estão próximos aos valores descritos por Fagliari et al. (1998) e Vásquez \& Herrera (2003) para a raça.

Ao comparar os componentes bioquímicos e hematológicos entre os dois grupos, não gestantes e gestantes, observa-se diferença significativa ( $\mathrm{p}<$ 0,05) entre as variáveis: albumina, ureia, AST, ALP, GGT, hemácias, hemoglobina e hematócrito. Os valores das variáveis albumina, ureia, hemácias, hemoglobina e hematócrito foram maiores para os animais que gestaram no período experimental. Já os valores de AST, ALP e GGT foram maiores para os animais que não gestaram (Tabela 1).

Os valores de albumina e ureia são componentes que indicam o metabolismo proteico dos animais e que suas concentrações têm relação com a disponibilidade de proteína na dieta do animal (Stradiotti Júnior \& Cosér, 2012). Neste experimento os animais estavam sobre o mesmo tratamento indicando que o aumento nas concentrações de albumina e ureia pode ser decorrente de um melhor aproveitamento dos componentes proteicos da dieta pelos animais do grupo gestante, portanto este melhor aproveitamento proporcionou um melhor desempenho reprodutivo, uma vez que estas tonaram-se gestantes.

González et al. (2000) observaram resultados semelhantes ao obtido neste experimento, no qual encontraram diferença de $0,16 \mathrm{~g} / \mathrm{dl}$ nas concentrações de albumina relacionado com a ocorrência de gestação em bovinos submetidas ao mesmo manejo nutricional.

O aumento nas concentrações dos componentes proteicos, como o observado no experimento, e nos componentes energético foram descritos na literatura associados a um melhor desempenho reprodutivo. Moriel et al. (2012), avaliando a suplementação energética e o desempenho reprodutivo de novilhas de corte, relataram maiores concentrações de glicose associada a maiores taxas de gestação no início da estação de acasalamento. Campaneli et al. (2010), ao estudarem o perfil 
metabólico e a função ovariana de búfalas jovens, Senosy et al. (2013), estudando a função ovariana de ovelhas submetidas a dieta com alto nível de energia e Samadi et al. (2013), analisando a interrelação entre nutrição, hormônios metabólicos e reestabelecimento da ovulação, também observaram o aumento nas concentrações dos componentes bioquímicos como glicose, colesterol, proteína total e ureia, associados a melhores resultados reprodutivos.

Tabela 1. Valores medidos do perfil bioquímico e hematológico de novilhas Nelore não gestante e gestante, criadas a pasto na região de Planaltina, Distrito Federal.

\begin{tabular}{|c|c|c|c|c|c|c|}
\hline & \multicolumn{3}{|c|}{ Não Gestantes } & \multicolumn{3}{|c|}{ Gestantes } \\
\hline & Média & $\begin{array}{l}\text { Desvio } \\
\text { padrão }\end{array}$ & $\begin{array}{l}\text { Coeficiente } \\
\text { de variação }\end{array}$ & Média & $\begin{array}{l}\text { Desvio } \\
\text { padrão }\end{array}$ & $\begin{array}{l}\text { Coeficiente } \\
\text { de variação }\end{array}$ \\
\hline Proteína Total (g/dl) & $7,46^{\mathrm{a}}$ & 0,73 & 9,78 & $7,46^{\mathrm{a}}$ & 0,77 & 10,38 \\
\hline Albumina (g/dl) & $3,01^{\mathrm{b}}$ & 0,47 & 15,79 & $3,16^{\mathrm{a}}$ & 0,49 & 15,63 \\
\hline Globulina (g/dl) & $4,45^{\mathrm{a}}$ & 0,85 & 19,13 & $4,31^{\mathrm{a}}$ & 0,96 & 22,34 \\
\hline Ureia (mg/dl) & $18,25^{\mathrm{b}}$ & 5,29 & 29,02 & $19,49^{\mathrm{a}}$ & 5,85 & 30,04 \\
\hline Colesterol (mg/dl) & $130,81^{\mathrm{a}}$ & 26,64 & 20,36 & $133,85^{\mathrm{a}}$ & 28,54 & 21,32 \\
\hline Glicose (mg/dl) & $69,64^{\mathrm{a}}$ & 14,81 & 21,26 & $71,31^{\mathrm{a}}$ & 15,20 & 21,32 \\
\hline Magnésio (mg/dl) & $2,44^{\mathrm{a}}$ & 0,64 & 26,23 & $2,40^{\mathrm{a}}$ & 0,62 & 25,76 \\
\hline Fósforo (mg/dl) & $5,88^{\mathrm{a}}$ & 1,58 & 26,93 & $5,68^{\mathrm{a}}$ & 1,63 & 28,65 \\
\hline Cálcio (mg/dl) & $9,79^{\mathrm{a}}$ & 1,93 & 19,74 & $9,65^{\mathrm{a}}$ & 1,85 & 19,13 \\
\hline AST(U/L) & $82,70^{\mathrm{a}}$ & 21,42 & 25,90 & $72,55^{\mathrm{b}}$ & 14,70 & 20,26 \\
\hline ALP (U/L) & $256,26^{\mathrm{a}}$ & 78,18 & 30,51 & $239,66^{\mathrm{b}}$ & 64,53 & 26,92 \\
\hline GGT (U/L) & $19,79^{\mathrm{a}}$ & 5,24 & 26,46 & $17,83^{\mathrm{b}}$ & 6,07 & 34,05 \\
\hline Leucócitos $\left(10^{3} / \mathrm{ml}\right)$ & $10,25^{\mathrm{a}}$ & 3,07 & 29,93 & $10,32^{\mathrm{a}}$ & 2,87 & 27,85 \\
\hline Hemácias $\left(10^{6} / \mathrm{ml}\right)$ & $9,01^{\mathrm{b}}$ & 1,80 & 19,98 & $9,34^{\mathrm{a}}$ & 1,48 & 15,86 \\
\hline Hemoglobina (g/dl) & $11,03^{\mathrm{b}}$ & 1,55 & 14,09 & $11,96^{\mathrm{a}}$ & 1,74 & 14,54 \\
\hline Hematócrito (\%) & $34,80^{\mathrm{b}}$ & 5,10 & 14,66 & $37,27^{\mathrm{a}}$ & 5,49 & 14,73 \\
\hline Plaqueta $\left(10^{3} / \mathrm{ml}\right)$ & $388,46^{\mathrm{a}}$ & 263,85 & 67,92 & $375,81^{\mathrm{a}}$ & 203,98 & 54,28 \\
\hline Fibrinogênio (mg/dl) & $406,51^{\mathrm{a}}$ & 319,44 & 78,58 & $411,85^{\mathrm{a}}$ & 370,18 & 89,88 \\
\hline
\end{tabular}

Letras minúsculas diferentes, na mesma linha, indicam diferença significativa $(\mathrm{p}<0,05)$ entre os grupos.

As alterações fisiológicas decorrentes da aproximação da puberdade, ocorrência da puberdade e gestação, também podem ser fatores que contribuíram com o aumento nas concentrações de albumina e ureia. Antunović et al. (2004) e Brito et al. (2006), trabalhando com ovelhas em diferentes condições fisiológicas, observaram que a condição do animal altera o metabolismo do mesmo, resultando em alteração dos componentes bioquímicos.

As variáveis AST, ALP e GGT são utilizadas para descrever o funcionamento hepático e o aumento destes componentes acima dos valores de referência indicam lesão hepática (González et al., 2011), condição não encontrada neste trabalho. As menores concentrações séricas das enzimas hepáticas para os animais que gestaram (AST 72,55 \pm 14,70 U/L; ALP 239,66 \pm 64,53 U/L; 17,83 \pm $6,07 \mathrm{U} / \mathrm{L}$ ) em relação as que não gestaram (AST $82,70 \pm 21,42 \mathrm{U} / \mathrm{L} ;$ ALP 256,26 \pm 78,18 U/L; GGT $19,79 \pm 5,24 \mathrm{U} / \mathrm{L})$ podem indicar uma melhor eficiência metabólica, pois, sob as mesmas condições observou-se maiores valores de albumina, ureia e melhor desempenho reprodutivo (Tabela 1). Segundo Stojević et al. (2005), as enzimas hepáticas são catalisadores de reações metabólicas de aminoácidos, carboidratos e suas concentrações estão relacionadas com a atividade celular. Os mesmos autores observaram alterações nas enzimas hepáticas decorrente de modificações metabólicas que ocorrem durante a lactação, associado a uma maior demanda de nutrientes nas fases de maior produção leiteira. Fagliari et al. (1998) também relataram mudanças nas concentrações enzimáticas em decorrência das modificações fisiológicas dos animais, diferentemente de Vieira et al. (2010) que atribuíram o aumento na atividade hepática decorrente da baixa qualidade das forragens entre períodos de avaliações no qual os animais foram submetidos. 
As modificações encontradas para valores hematológicos podem ser resultantes da melhor condição metabólica dos animais que gestaram, pois estes estavam sobre as mesmas condições ambientais o que não justifica as alterações hematológicas por influência do meio ambiente, segundo Delfino et al. (2012), os componentes hematológicos além de sofrerem alterações decorrentes de patologias, estes sofrem modificações influenciadas pelo meio no qual o animal está submetido.

As alterações da contagem de hemácias justificamse por um possível aumento do metabolismo do grupo das novilhas gestantes, o que resulta em um maior consumo de oxigênio e consequentemente uma maior necessidade de hemácias para transporte deste. Segundo Cunninghan (2008), a contagem total de hemácias está relacionada com a demanda do organismo por oxigênio, ou seja, o aumento desta demanda eleva a quantidade de hemácias. Os maiores valores de hemoglobina e hematócrito estão relacionados com o aumento das contagens de hemácias, uma vez que a hemoglobina é constituinte proteico destas células responsável pelo transporte de oxigênio e o hematócrito consiste nas concentrações de hemácias no sangue. Vale salientar que os componentes hematológicos são utilizados na clínica animal como método auxiliar de avaliação de saúde e são escassos trabalhos que descrevem a relação destes componentes com o desempenho reprodutivo.
Na tabela 2 estão descritos os valores de correlação entre o estado fisiológico gestante com as variáveis idade, peso e do perfil bioquímico e hematológico. Pode-se destacar a correlação mediana entre a variável gestação com a idade e peso, o que se espera, pois observa-se o aumento da taxa de gestação nos rebanhos decorrente do aumento da idade e do peso das novilhas na estação de acasalamento.

A correlação entre gestação e proteína total, apesar de baixa, mostra-se positiva, o que sugere um aumento nas concentrações séricas de proteína nos animais que gestaram. Este aumento pode ser resultante do melhor metabolismo destas novilhas devido a gestação. A associação entre o aumento nas concentrações dos componentes proteicos e melhores índices reprodutivos e produtivos foram descritos por González et al. (2000) e Stradiotti Júnior \& Cosér (2012).

Os resultados das correlações entre gestação com as variáveis globulina, hemácias e plaquetas, podem ser decorrentes da elevada idade das novilhas ao se tornarem gestantes. $\mathrm{O}$ aumento da globulina pode ocorrer por uma maior produção de anticorpos, pelo maior tempo de exposição do animal as condições ambientais. Já a redução dos componentes sanguíneos pode ser resultante de uma menor atividade metabólica dos animais, por estarem mais próximos da idade adulta.

Tabela 2. Correlação entre idade, peso, puberdade, gestação e perfil bioquímico e hematológico de novilhas Nelore criadas a pasto na região de Planaltina, Distrito Federal.

\begin{tabular}{l|l}
\hline & Gestação \\
\hline Gestação & 1,00 \\
Idade & $0,381^{* *}$ \\
Peso & $0,382^{* *}$ \\
Proteína total & $0,165^{* *}$ \\
Magnésio & $-0,003$ \\
Fósforo & $0,103^{*}$ \\
Cálcio & 0,064 \\
Albumina & 0,057 \\
Colesterol & 0,074 \\
Ureia & $-0,027$ \\
AST & $-0,043$ \\
ALP & $-0,050$ \\
GGT & $-0,031$ \\
Glicose & $-0,077$ \\
Globulina & $0,105^{*}$ \\
Leucócitos & 0,065 \\
Hemácias & $-0,158^{* *}$ \\
Hemoglobina & $-0,021$ \\
Hematócrito & $-0,075$ \\
Plaqueta & $-0,185^{* *}$ \\
Fibrinogênio & $-0,001$ \\
\hline Indica corrac̃â significativa p &
\end{tabular}

* Indica correlação significativa $\mathrm{p}<0,5$

** Indica correlação significativa $\mathrm{p}<0,001$ 
As variações entre as características idade, peso, gestação e do perfil bioquímico e hematológico foram representadas através de um gráfico de componentes principais (Figura 2). Os primeiros dois componentes explicam $43 \%$ das variações entre as características. O primeiro auto vetor mostra que com o aumento da idade e peso favorece a ocorrência da gestação e associado a estas modificações têm-se o aumento das concentrações de proteína total, globulina, magnésio, GGT, AST, hemoglobina, hematócrito e na contagem total de hemácias. No segundo auto vetor é possível visualizar o aumento das concentrações séricas de fósforo, cálcio, magnésio, proteína total, globulina, albumina, ureia, glicose, GGT, AST, ALP e fibrinogênio relacionado com o aumento da idade, peso e ocorrência de gestação. As interações observadas podem ser justificadas pelas alterações fisiológicas que ocorrem no animal com o aumento da idade, bem como devido a ocorrência da puberdade e da gestação, as modificações bioquímicas e hematológicas são semelhantes as descritas por Fagliari et al. (1998), Antunović et al. (2004) e Brito et al. (2006).

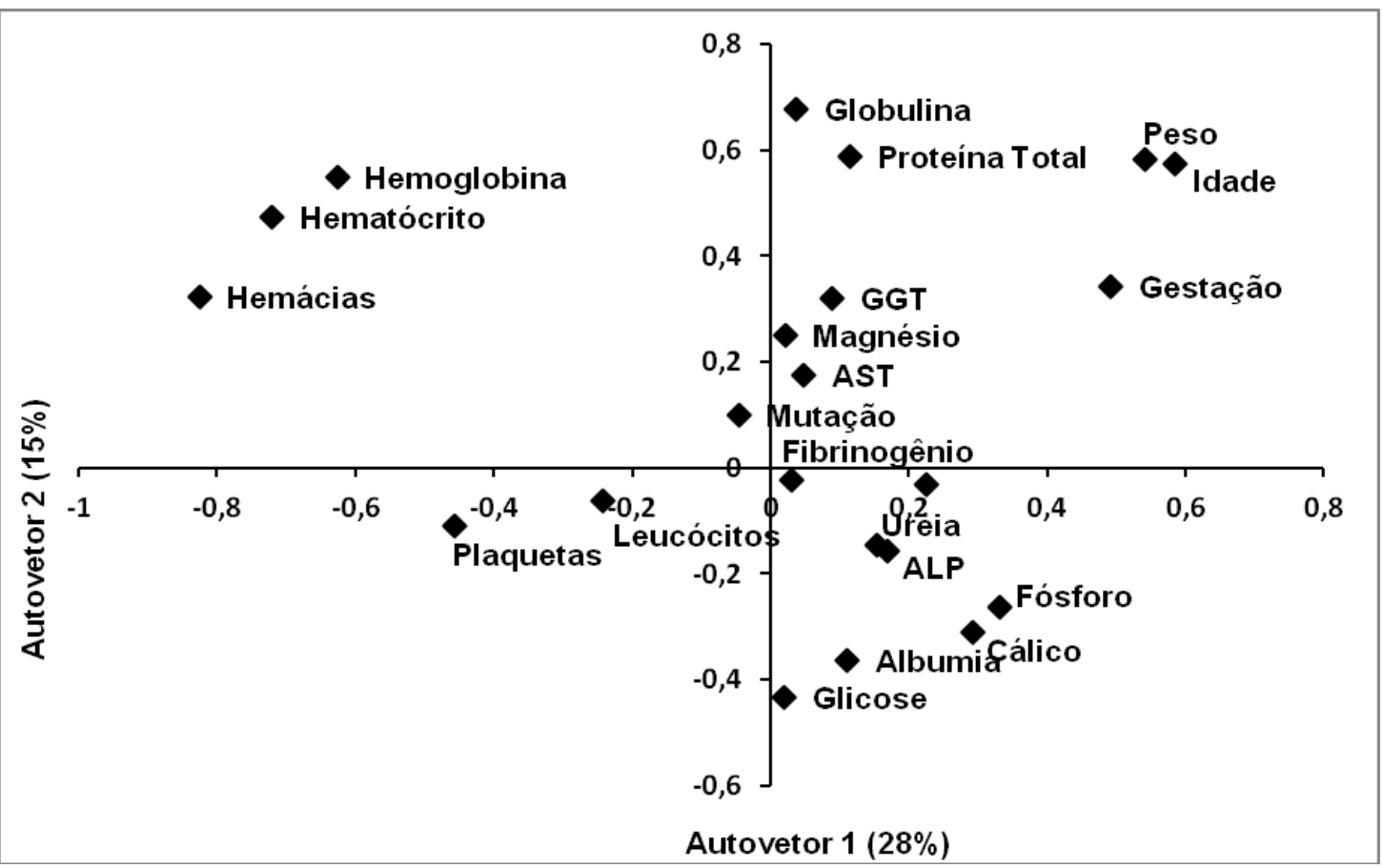

Figura 2. Representação gráfica dos componentes principais das características produtivas e do perfil bioquímico e hematológico das novilhas Nelore criadas a pasto na região de Planaltina, Distrito Federal.

A tabela 3 indica quais variáveis têm maior probabilidade de influenciar a ocorrência da gestação. Os resultados obtidos confirmam as observações de que além do ganho em peso e o aumento da idade, as modificações nos componentes bioquímicos e hematológicos podem ser resultado da ocorrência da gestação em novilhas Nelore. O aumento do ganho de peso e da idade das fêmeas influenciam na ocorrência da gestação, informações semelhantes as descritas por VIEIRA et al. (2006) e BATISTA et al. (2012) que observaram o aumento na taxa de gestação associado ao aumento da idade e do peso dos animais. Além dessas variáveis o aumento nas concentrações de proteína total e contagem total de leucócitos e a redução das concentrações de AST e GGT, possui relação positiva com a ocorrência da gestação em novilhas.

Tabela 3. Análise de regressão logística para a ocorrência de gestação em novilhas em relação às variáveis idade, peso e do perfil bioquímico e hematológico.

\begin{tabular}{l|cccc}
\hline Parâmetro & Estimativa & Erro padrão & Qui - quadrado & Valor de $\mathrm{p}$ \\
\hline Idade & 0,442 & 0,102 & 18,880 & $<0,0001$ \\
Peso & 0,014 & 0,006 & 5,574 & 0,018 \\
Proteína total & 1,055 & 0,379 & 7,756 & 0,005 \\
AST & $-0,065$ & 0,021 & 9,366 & 0,002 \\
GGT & $-0,136$ & 0,053 & 6,463 & 0,011 \\
Leucócitos & 0,241 & 0,094 & 6,586 & 0,010 \\
\hline
\end{tabular}




\section{CONCLUSÃO}

A ocorrência de gestação em novilhas Nelore criadas a pasto apresentou relação com as variáveis, proteína total, alumina, ureia, AST, ALP, GGT do perfil bioquímico e com as variáveis hemácias, hematócrito, hemoglobina e leucócitos do perfil hematológico. Estas alterações metabólicas podem indicar uma melhor condição fisiológica das novilhas o que favoreceu a ocorrência da gestação. Portanto o acompanhamento do perfil bioquímico e hematológico pode ser uma ferramenta auxiliar para identificar novilhas como melhor metabolismo, melhorando o desempenho reprodutivo na estação de monta.

\section{AGRADECIMENTOS}

Agradecemos ao Conselho Nacional de Desenvolvimento Científico e Tecnológico (CNPq) pelo financiamento do projeto.

\section{REFERÊNCIAS}

ANTUNOVIĆ, Z.; ŠPERANDA, M.; STEINER, Z. The influence of age and the reproductive status to the blood indicators of the ewes. Archiv Tierzucht, Dummerstorf, V.47, n.3, p.265-273, 2004

BATISTA, D. S. N.; ABREU, U. G. P.; FERRAZ FILHO, P. B.; ROSA, A. N. Índices reprodutivos do rebanho Nelore da fazenda Nhumirim, Pantanal da Nhecolândia. Acta Scientiarum, Animal Sciences, Maringá, v. 34, n. 1, p. 71-76, 2012.

BERETTA, V.; LOBATO, J. F. P.; MIELITZ NETTO, C. G. A. Produtividade e eficiência biológica de sistemas pecuários de cria diferindo na idade das novilhas ao primeiro parto e na taxa de natalidade do rebanho no Rio Grande de Sul. Revista Brasileira de Zootecnia, Viçosa, v.30, n.4, p.1278-1286, 2001.

BOLIGON, A. A.; ALBUQUERQUE, L. G. Genetic parameters and relationships of heifer pregnancy and age at first calving with weight gain, yearling and mature weight in Nelore cattle. Livestock Science, n.141, p.12-16, 2011.

BOLIGON, A. A.; VOZZI, P. A.; NOMELINI, J.; RORATO, P. R. N.; BEZERRA, L. A. F.; LÔBO, R. B. Parâmetros genéticos para idade ao primeiro parto estimados por diferentes modelos para rebanhos da raça Nelore. Ciência Rural, Santa Maria, v.38, n.2, p.432-436, 2008

BRITO, M. A.; GONZÁlEZ, F. D.; RIBEIRO, L. A.; CAMPOS, R.; LACERDA, L. BARBOSA, P. R.; BERGMANN, G. Composição do sangue e do leite em ovinos leiteiros do sul do Brasil: variações na gestação e na lactação. Ciência Rural, Santa Maria, v.36, n.3, p.942-948, 2006.

CABRAL, J. F.; LEÃO, K. M.; SILVA, M. A. P.; BRASIL, R. B. Indução do estro em novilhas Nelore com implante intravaginal de progesterona de quarto uso. Revista Brasileira de Ciência Veterinária, Niterói, v. 20, n. 1, p. 49-53, 2013.

CAMPANELI, G.; BARUSELLI, P. S.; VECCHIO, D.; PRANDI, A.; NEGLIA, G.; CARVALHO, N. A. T.; SALES, J. N. S.; GASPARRINI, B.; DOCCHI, M.J. Growth, metabolic satatus and ovarian function in buffalo (Bubalus bubalis) heifers fed a low energy or high energy diet. Animal Reproduction Science, Edinburg, n.122, p.74-81, 2010.
CARDOSO, D.; NOGUEIRA, G. P. Mecanismos neuroendócrinos envolvidos na puberdade de novilhas. Arquivos de Ciências Veterinárias e Zoologia da Unipar, Umuarama, v.10, n.1, p.59-67, 2007.

CLARO JÚNIOR, I.; SÁ FILHO, O. G.; PERES, R. F. G.; AONO, F. H. S.; DAY, M. L.; VASCONCELOS, J. L. M. Reproductive performance of prepubertal Bos indicus heifers after progesterone-based treatments. Theriogenology, Stoneham, n.74, p. 903-911, 2010.

CORDOVA, I. F. M.; CIFFONI, E. M. G. Correlação entre a taxa de prenhez, idade, peso, medidas lineares e escore corporal, em novilhas Nelore de 13 a 24 meses, na região norte do Mato Grosso - Brasil. FAZU em Revista, Uberaba, n.7, p. 172 - 176, 2010.

CUnNinghan, J. G. Tratado de Fisiologia Veterinária. $4^{\circ}$ Edição, Editora Guanabara Koogan, Rio de Janeiro, 2008. 579p.

DELFINO, L. J. B.; SOUZA, B. B.; SILVA, R. M. N.; SILVA, W. W. Influência bioclimatológica sobre os parâmetros hematológicos de bovinos leiteiros. ACSA - Agropecuária Científica no Semi-Árido, Patos, v.8, n.1, p.23-27, 2012.

EUCLIDES, V. P. B.; EUCLIDES FILHO, K.; COSTA, F. P.; FIGUEIREDO, G. R. Desempenho de novilhos F1s AngusNelore em pastagens de Brachiaria decumbens submetidos a diferentes regimes alimentares. Revista Brasileira de Zootecnia, Viçosa, v. 30, n. 2, p.470-481, 2001

FAGLIARI, J. J.; SANTANA, A. E.; LUCAS, F. A.; CAMPOS FILHO, E.; CURI, P. R. Constituintes sanguíneos de bovinos lactantes, desmamados e adultos das raças Nelore (Bos indicus) e Holandesa (Bos taurus) e de bubalinos (Bubalus bubalis) da raça Murrah. Arquivo Brasileiro de Medicina Veterinária e Zootecnia, Belo Horizonte, v.50, n.3, p.263-271, 1998.

FIOL, C.; QUINTANS, G.; UNGERFELD, R. Response to biostimulation in Peri-puberal beef heifers: influence of malefemale proximity and heifer's initial body weight. Theriogenology, Stoneham, n.74, p.569-575, 2010.

GOJJAM, Y.; TOLERA, A.; MESFIN, R. Management options to accelerate growth rate and reduce age at first calving in Friesian-Boran crossbred heifers. Tropical Animal Health and Production, Edinburgh, v.43, p.393-399, 2011.

GONZÁLEZ, F. D.; MUIÑO, R.; PEREIRA, V.; CAMPOS, R. BENEDITO, J. L. Relationship among blood indicators of lipomobilization and hepatic function during early lactation in high-yielding dairy cows. Journal of Veterinary Science, Suwon, v.12, n.3, p.251-255 2011

GONZÁLEZ, F. H. D., CONCEIÇÃO, T. R., SIQUIERA, A. J. S., LA ROSA, V. L. Variações sanguíneas de uréia, creatinina, albumina e fósforo em bovinos de corte no Rio Grande do Sul. A Hora Veterinária, Porto Alegre, v.20, n. 117, p.59-62, 2000

LIMA, F. G.; FIORAVANTI, M. C. S. Diagnóstico laboratorial de hepatopatias aplicado a bovinos criados no Brasil. Revista CFMV, Brasília, n.51, p.60-75, 2010

MENEZES, L. M.; BRAUNER, C. C.; PIMENTEL, M. A. Efeitos da bioestimulação sobre a performance reprodutiva em bovinos de corte. Archivos de Zootecnia, Cordoba, v. 59, p.113, 2010.

MORIEL, P.; COOKE, R. F.; BOHNERT, D. W.; VENDRAMINI, J. M. B.; ARTHINGTON, J. .D. Effects of energy supplementation frequency and forage quality on performance reproductive and physiological responses of replacement beef heifers. Journal of Animal Science, Savoy, n.90, p. 2371-2380, 2012. 
NOGUEIRA, G. P. Puberty in South American Bos indicus zebu cattle. Animal Reproduction Science, Edinburg, v.82-83, p.361-372, 2004

OLIVEIRA, C. M. G.; OLIVEIRA FILHO, B. D.; GAMBARINI, M. L.; VIU, M. A. O.; LOPES, D. T.; SOUSA, A. P. F. Effects of biostimulation and nutritional supplementation on pubertal age and pregnancy rates of Nelore heifers (Bos indicus) in a tropical environment. Animal Reproduction Science, Amsterdam, v.113, p.38-43, 2009.

PILAU, A.; LOBATO, J. F. P. Suplementação energética préacasalamento aos 13/15 meses de idade para novilhas de corte: desenvolvimento e desempenho reprodutivo. Revista Brasileira de Zootecnia, Viçosa, v.38, n.12, p.2482-2489, 2009.

REIS, R. A.; RUGGIERI, A. C.; OLIVEIRA, A. A.; AZENHA, M. V.; CASAGRANDE, D. R. Suplementação como estratégia de produção de carne de qualidade em pastagens tropicais. Revista Brasileira de Saúde e Produção Animal, Salvador, v.13, n.3, p.642-655, 2012.

RORIE, R. W.; BILBY, T. R.; LESTER, T. D. Application of electronic estrus detection technologies to reproductive management of cattle. Theriogenology, Stoneham, v.57, p.137$148,2002$.

SAMADI, F.; PHILLIPS, N. J.; BLACHE, D.; MARTIN, G. B.; D'OCCHIO, M. J. Interrelationships of nutrition, metabolic hormones and resumption of ovulation in multiparus suckled buf cows on subtropical pastures. Animal Reproduction Science, Edinburg, Article in Press, 2013.

SCHALM, W.; JAIN, N. C.; CARROLL, E. J. Hematología veterinaria. Buenos Aires:Hemisferio Sur, 1981. $856 \mathrm{p}$

SENOSY, W.; ABDEL-RAHEEM, Sh. M.; ABD-ALLAH, M.; FAHMY, S.; HASSAN, E. H.; DERAR, R. I. Effect of transient high-energy diet Just after ovulation on ovarian performance and metabolic status in cyclic ewes. Small Ruminant Reserch, Amsterdan, n.109, p.152-155, 2013.

SERENO, J. R. B.; PElleGRIN, A. O.; LARA, M. A. C.; ABREU, U. G. R. de; SERENO, F. T. P. S.; CHALITA, L. V. A. S. Precocidad sexual de novillas de la raza Pantaneira frente a las razas Nelore y mestizas Pantaneira x Nelore en el Pantanal brasileño. Archivos de Zootecnia, Córdoba, v. 50, p.153-157, 2001.

SHIOTSUKI, L.; SILVA, J. A. II de V.; ALBUQUERQUE, L. G. Associação genética de prenhez aos 16 meses com o peso à desmama e o ganho de peso em animais da raça Nelore. Revista Brasileira de Zootecnia, Viçosa, v. 38, n. 7, p. 1211-1217, 2009.

SILVA, J. A. de V.; DIAS, L. T.; ALBUQUERQUE, L. G. de. Estudo genético da precocidade sexual de novilhas em um rebanho Nelore. Revista Brasileira de Zootecnia, Viçosa, v. 34, n. 5, p.1568-1572, 2005.

Statistical Analysis System - SAS. System for Microsoft Windows: release 9.1. Cary: 2004. CD-ROM.

STOJEVIĆ, Z.; PIRS̆LJIN, J.; MILINKOVIĆ-TUR, S.; ZDELAR-TUK, M.; LJUBIĆ, B. B. Activities of AST, ALT and GGT in clinically healthy dairy cows during lactation and in the dry period. Veterinarski Arhiv, Zagreb, v.75, n.1, p.67-73, 2005 .

STRADIOTTI JÚNIO, D.; COSÉR, A. C. Perfil metabólico: produção e reprodução de bovinos. In.:DEMINICIS, B. B.; MARTINS, C. B.; SIQUEIRA, J. B. Tópicos especiais em Ciência Animal I: coletânea da $1^{\text {a }}$ Jornada Científica da PósGraduação em Ciências Veterinárias da Universidade Federal do Espírito Santos. Alegre, Editora CAUFES, 2012. $169 \mathrm{p}$.

VÁSQUEZ, E. F. A.; HERRERA, A. del P. N. Concentração plasmática de cortisol, uréia, cálcio e fósforo em vacas de corte mantidas a pasto suplementadas com levedura de cromo durante a estação de monta. Ciência Rural, Santa Maria, v.33, n.4, p.743-747, 2003.

VAZ, R. Z.; LOBATO, J. F. P. Efeito da idade de desmame no desempenho reprodutivo de novilhas de corte exposta à reprodução aos 13/15 meses de idade. Revista Brasileira de Zootecnia, Viçosa, v.39, n.1, p.142-150, 2010a.

VAZ, R. Z.; LOBATO, J. F. P. Efeito da idade do desmame no desenvolvimento de novilhas de corte até os 14/15 meses de idade. Revista Brasileira de Zootecnia, Viçosa, v.39, n.2, p.289-298, 2010b.

VIEIRA, A.; LOBATO, J. F. P.; CORRÊA, E. S.; TORRES JÚNIOR, R. A. A.; COSTA, F. P. Desenvolvimento e desempenho reprodutivo de novilhas Nelore criadas a pasto nos cerrados do Centro-Oeste brasileiro. Revista Brasileira de Zootecnia, Viçosa, v.35, n.1, p.186-192, 2006.

VIEIRA, M. B.; SCHWEGLER, E.; GOULART, M. A.; SILVA, V. M.; LESTON, J.; TABELEÃO, V. C.; FONTOURA JÚNIOR, J. A.; DEL PINO, F. A. B.; CORRÊA, M. N. Avaliação do perfil metabólico de touros em diferentes fases do ciclo reprodutivo. Brazilian Journal of Veterinary Research and Animal Science, São Paulo, v.47, n.1, p.31-37, 2010.

WITTWER, F. Marcadores bioquímicos no controle de problemas metabólicos nutricionais em gado de leite. In: GONZALEZ, F. H. D., BARCELlOS, J. O., OSPINA, H., RIBEIRO, L. A. O. Perfil metabólico em ruminantes: seu uso em nutrição e doenças nutricionais. Porto Alegre, Gráfica Universidade Federal do Rio Grande do Sul, p.53-62, 2000. 